\title{
High-Rise Residential Reinforced Concrete Building Optimisation
}

\author{
Haibei Xiong1, Miguel Angel Hidalgo Calvo ${ }^{2}$ \\ ${ }^{1}$ Department of Structural Engineering, Tongji University, Shanghai, China \\ ${ }^{2}$ Department of Civil Engineering, Polytechnic University of Catalonia/Tongji University (UPC), Barcelona, Spain \\ Email: xionghaibei@tongji.edu.cn, ma.hidalgo.calvo@gmail.com
}

Received 7 November 2015; accepted 22 December 2015; published 28 December 2015

Copyright (C) 2015 by authors and Scientific Research Publishing Inc.

This work is licensed under the Creative Commons Attribution International License (CC BY). http://creativecommons.org/licenses/by/4.0/

(c) (i) Open Access

\begin{abstract}
In the last few decades structure optimisation has become a main task in a civil engineering project. As a matter of fact, due to the complexity and particularity of every structure, the great amount of variables and design criteria to considerate and many other factors, a general optimisation's method is not simple to formulate. As a result, this paper focuses on how to provide a successful optimisation method for a particular building type, high-rise reinforced concrete buildings. The optimization method is based on decomposition of the main structure into substructures: floor system, vertical load resisting system, lateral load resisting system and foundation system; then each of the subsystems using the design criteria established at the building codes is improved. Due to the effect of the superstructure optimisation on the foundation system, vertical and lateral load resisting system is the last to be considered after the improvement of floor. Finally, as a case example, using the method explained in the paper, a 30-story-high high-rise residential building complex is analysed and optimised, achieving good results in terms of structural behaviour and diminishing the overall cost of the structure.
\end{abstract}

\section{Keywords}

Structure Optimisation, High-Rise Residential Reinforced Concrete Buildings, Shear-Wall Structure, Deep Piles, Post Grouting

\section{Introduction}

In our society, where the economic cost of a structure is clearly of great priority in a project, structure design has become a main factor of attention; however with the help of finite element programs which are available nowadays, structure design is a simple task. Nevertheless, for a same building there are different possible structure 
layouts, with different structural behaviours and economic costs; this concept leads to the optimisation of structures.

Structure optimisation is the procedure of improving a preliminary design established by the architectural layout and the engineer's opinion without exceeding the design criteria (strength, serviceability, stability and human comfort). This improvement is done bearing in mind the requirements on each element, cross-section and structural member, and should be as near as possible to the limit established by the criteria to achieve a better economic reduction on the project.

Nevertheless this topic is too broad to be fully discussed in this paper; as a result this research focuses solely on the optimisation of high-rise residential reinforced concrete buildings. The particularities of such structures are shear-wall structure as lateral load and vertical load resisting system, with connecting and secondary beams, two-way slab as gravitational floor system and a raft and driven piles as deep foundation system. In order to reduce the scope of the research, the optimisation will focus on several aspects of the main structural elements: slab, shear wall, beams, piles and raft.

In addition to the normal circumstances of a building, the research includes the effect of lateral loads, with special attention to earthquake and wind load. For this type of high-rise structure, the two lateral loads are determinant in the design of the structure. Therefore, the main challenges and focus of the research will be aimed at solving the effect of an earthquake on the foundation and the shear-wall system.

\section{Structure Optimisation}

\subsection{Optimisation Order}

In order to simplify the problem, firstly we will have to decompose the whole structure in subsystems, then select a series of optimisation variables and study them separately. Based on Professor P. Jayachandran's [1] study, I have determined the decomposition of the structure in the following subsystems (Figure 1).

The aim of the separation of the structure in sub-structure is to study more comprehensively a single optimisation variable, then observe the effect on the structure. The following step after determine the subsystem, is to determine the order of optimising and the criterion of optimisation chosen in each of them.

But how to determine the most appropriate order [2], we just have to consider the effect of the optimisation of that element will have on the other elements and the whole structure. Because of foundation system being the first system to be built in a structure, logically it should be the first one to be optimised; however there is a direct relation of the foundation system and the load applied on the foundation. As a result, we can conclude it to be the last subsystem to optimise.

Furthermore the obvious answer to the question of the first optimising step is the floor system; because the floor system only depends on the other subsystem as boundary conditions and the main important factors are the loads applied over them, which are invariables in the structure.

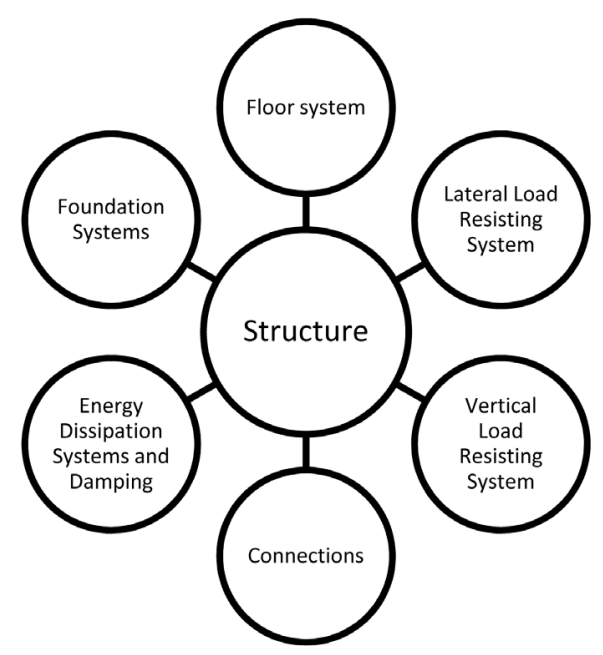

Figure 1. Structure decomposition. 
The own characteristic shear wall, being vertical and lateral load resisting systems of the high-rise reinforced concrete structure, give the second and third step of optimisation. Finally the foundation system is optimised (Figure 2).

The effect of the optimisation of one of the sub-system will affect the other elements, so as after the optimisation of one subsystem one shall consider what effect will have on the other ones. For example, the reduction of slab thickness will provide a lower load in every floor and will affect the lateral load and vertical load resisting systems requirements, obviously the foundation system requirements also will be reduced. Then if we consider a different shear wall layout in the structure it will have an effect, in terms of boundary conditions, in the floor system. Therefore the whole optimisation process is an iterative process until the final solution is found.

\subsection{Optimisation Procedure}

Once the optimisation order is determined, the actual optimisation is the next step on the procedure [3] [4], but how do we perform this optimisation is the most important step to determine in an optimisation process. As has been introduced in the last part of the chapter, there are a great number of variables to optimise and if we consider the interaction between members there are almost an unlimited possibilities of optimisation. In order to simplify and with the aim of reducing the cost as much as possible, we should select one or several variables in each subsystem to be optimised. Furthermore we must consider design criteria as a goal of the optimisation, in this case, the criteria are fixed, but we still can focus on one or several of them. This chapter will not discuss the criteria, but the chapter 3 will. However there will be a mention of them in each subsystem optimisation procedure.

Since the floor system is the first one to be optimised in our optimisation process; we will start the introduction of the optimisation procedure with it. The floor system is one of the most weight consuming systems in a building, around $20 \%$. If we take into account the costs of the slab system separately: formwork consumes $45 \%$ - 55\% of the slab cost, therefore a regular slab and without changes in the layout and shape in every floor will give us a better result; $30 \%$ - 35\% of the cost is given by the concrete, including placing and finishing; and a lesser part is given by the steel reinforcement. We can conclude that for a shear wall layout, the better solution shall be to supply it with a flat slab; another conclusion we is that the most important factor to optimise is the volume of concrete, but not the concrete grading, because of its low difference price. Once we determined the variables of optimisation, in this case flat slab and slab thickness, we shall set design criteria, apart from the strength and others requirements: the most important one is the deflection. However if we consider the criteria, there are two possible ways of achieving these deflection requirements: one is using the code established minimum thickness, the second one a maximum computed deflection considering the long-term deflection. Finally we can proceed with the optimisation, in this thesis it has been chosen the commercial software SAFE 2014 to carry out a long term analysis of the concrete, in which creep and shrinkage are considered.

Once the floor system is optimised, the original model shall be updated and restudied, in that case, for the upper structure (lateral resisting load system) I selected the commercial software ETABS 2014 to analyse and carry out the optimisation procedure. After the optimisation process of the floor is achieved, the behaviour of the new structure will guide the optimisation of the lateral load and vertical load resisting system. In this case there are also multiple variables to consider but the main ones are focused on the main structural element, the shear wall [5]. The main parameters that shall be considered in the shear wall are: wall thickness and layout being, plus a study of the concrete grading along the height and a possible change of model openings, of a connecting beam to a wall system. Again and similar to the slab, the strength, bond, serviceability requirements must be satisfied, but the main design criteria for the optimisation of this two subsystems is the inter-story drift. After the optimisation of the system we will need to check if the floor system does still satisfy the computed long-term deflection requirements.

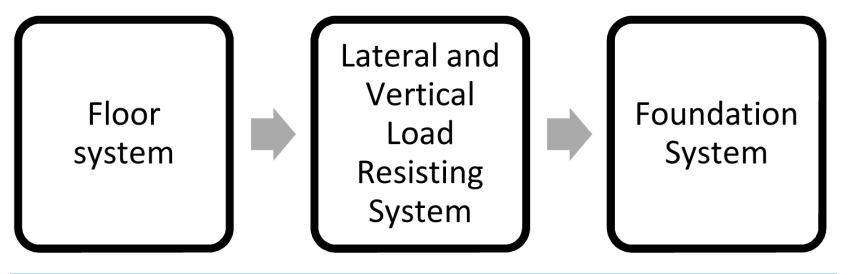

Figure 2. Optimisation order. 
After the optimisation of floor system, lateral load and vertical load resisting system, the whole superstructure can be considered as optimised. The following step will be to import the actions of the superstructure to the foundation. The software chosen to model and optimise the foundation system is the commercial software SAFE 2014. In this case, the deep foundation system consists of two main parts: raft and piles [6]. For the optimisation of the whole, we will select different parameters for each of them; for the raft, the thickness is the optimisation parameter and the main design requirement is the punching shear; for the piles the main optimisation parameter is the piles length and diameter, piles placed under the shear wall, furthermore we will consider the possibility of using post grouted, the main design criteria will be the ultimate strength under lateral loads. Moreover a comprehensive settlement of the whole foundation shall be achieved, avoiding differential settlements and other possible problems.

As a conclusion we can say that the procedure has only a few variables from the all the possibilities. Table 1 summarizes this part of the paper.

This optimisation summary shows the main optimisation parameters to consider, however there is an extra effect that will be really important in the satisfaction of the requirements, torsion. High-rise residential buildings wall layout is clearly non-regular, which in some cases will give a heavy torsional effect under lateral loads, such as earthquake.

So, in order to avoid the torsional effect phenomenon we will have to firstly observe and understand the initial structure, determine whether there is or there isn't a torsional problem that might be even worse with the proposed optimisation, having a counter effect. In case there is, we will try to compensate it before starting with the shear wall optimisation. The torsional effect can be solved simply by placing as near as possible the mass centre and the rigidity centre of each floor, this might look difficult, but with the increase of the thickness and layout modification of some shear walls the effect can be easily achieved.

\section{Design Criteria}

\subsection{Overview}

This section will only highlight the fragments of the code which are used in a posterior case example of the Golden City. Which will have the aim of achieve a good structure performance in terms of strength, serviceability, stability and human comfort, with the benefits of an economical cost saving.

Firstly we should determine the basic requirements for a high-rise building with shear wall structure and deep foundation as a foundation system, being this kind of building the objective of the study in situ. Then use these criterions to modify the original structure and achieve the optimisation.

Building optimisation must be followed by specific design criteria. As for have a common criterion, these design criteria are given by the already established building codes and the ones related to the main one, such as Eurocode for Europe, IBC for the United States... Due to the non-common requirements in each and every code, the final optimisation will vary, and as a result the selection of the code not only will determine the whole optimisation process but also will affect the structures final behaviour.

With the aim to determine the optimisation criteria, and even though I am a European citizen, I personally have chosen the IBC 2013 Code [7] with the corresponding related codes, mainly ACI 318 [8] and ASCE-7 [9],

Table 1. Optimisation summary.

\begin{tabular}{|c|c|c|c|}
\hline Subsystem & Optimisation element & Optimisation parameter & Design criteria \\
\hline Floor system & Slab & $\begin{array}{l}\text { Slab thickness } \\
\text { Flat slab }\end{array}$ & Deflection \\
\hline $\begin{array}{c}\text { Lateral resisting and } \\
\text { vertical resisting system }\end{array}$ & Shear wall & $\begin{array}{c}\text { Thickness } \\
\text { Layout } \\
\text { Concrete grading } \\
\text { Openings }\end{array}$ & Drift \\
\hline \multirow[t]{2}{*}{ Foundation system } & Piles & $\begin{array}{l}\text { Diameter and length } \\
\text { Placing under walls } \\
\text { Post grouting }\end{array}$ & Ultimate strength \\
\hline & Raft & Thickness & $\begin{array}{l}\text { Punching shear } \\
\text { Ultimate strength }\end{array}$ \\
\hline
\end{tabular}


concrete and load codes respectively. IBC is the United States building code, its aim is to establish the minimum regulation for buildings systems using prescriptive and performance-related provision so that the public health and safety in all communities is safeguarded. IBC being the main code that collects the different requirements of other codes, hence this thesis background of high-rise residential reinforced concrete buildings is it really important to also consult the ACI-318, written by American Concrete Institute (ACI), as much as the load code ASCE-07 for further understanding of wind, earthquake and other non-static loads.

\subsection{Strength Requirements}

For concrete elements, the main ones in our high-rise building the ACI 318 provide a series of strength requirements. These structures and structural members shall be designed to have design strength at every section higher or equal of the required strength calculated by the load combinations stipulated. The required ultimate strength in each member is the maximum of the following seven load combination, the effect of the different factored loads shall be considered individually.

$$
\begin{gathered}
U=1.4 D \\
U=1.2 D+1.6 L+0.5(\operatorname{Lr} \text { or } S \text { or } R) \\
U=1.2 D+1.6(\operatorname{Lr} \text { or } S \text { or } R)+(1.0 L \text { or } 0.5 W) \\
U=1.2 D+1.0 W+1.0 L+0.5(\operatorname{Lr} \text { or } S \text { or } R) \\
U=1.2 D+1.0 E+1.0 L+0.2 S \\
U=0.9 D+1.0 W \\
U=0.9 D+1.0 E
\end{gathered}
$$

\subsection{Stress Requirements}

IBC code provides two different ultimate conditions for every structural member, cross-section and connection; one in terms of ultimate strength, LRDF method, and a second one in terms of allowable stress design, namely ASD method.

Stress design is also a valid goal in our structures design, IBC code provides basic load combinations where the allowable working stress design is considered.

$$
\begin{gathered}
U=D \\
U=D+L \\
U=D+(L r \text { or } S \text { or } R) \\
U=D+(0.6 W \text { or } 0.7 E) \\
U=D+0.75 L+0.75(0.6 W)+0.75(L r \text { or } S \text { or } R) \\
U=D+0.75 L+0.75(0.7 E)+0.75 S \\
U=0.75 D+0.75 W \\
U=0.6 D+0.7 E
\end{gathered}
$$

\subsection{Deflection Requirements}

Slabs and beams are the main members subjected to large deflections. Therefore are the two elements to be considered in this part of the thesis, with special attention to the deflection in the slab which will be a huge optimisation parameter for the total volume of concrete consumed and the weight of the structure that will affect the foundations and the dynamic behaviour of the whole structure.

The requirements for the deflection of members, beams and slab, are determined in terms of maximum length of the structural member and boundary conditions of it, simply supported, one end continuous, both end continuous or cantilever, plus the different consideration of prestressed and non-prestressed and one-way and twoways slabs.

Nevertheless the thickness guidelines can be ignored if we take into account a finite element analysis of the members under flexure. In addition to the tables of minimum thickness the American code provides a set of 
maximum permissible computed deflections reflected on the Table 2 directly extracted from the ACI 318 code.

This computed deflections will permit us to diminish the thickness of the different structural members, with a FEM analysis that satisfies the displacement limitations as Table 2.

\subsection{Story Drift Requirements}

Design story drift is considered as the difference of the drift of two consecutive floors measured from the mass centre of them. ASCE 07 provides a table format data where the maximum allowable drift are shown (Table 12.12-1), the Table 3 extracts only the maximum drift concerning to a shear wall lateral system type resisting building.

Nevertheless in real design of structures, due to possible damage on non-structural partition walls, structural engineers tend to have a safer maximum drift around 1/400 times the height of the floor.

\section{Case Study: Golden City}

\subsection{Introduction}

This section of the thesis shows the optimisation process of a series of buildings still under construction situated in Yangon region, which is one of the most populated and socio-economically important cities in Myanmar. The buildings to be optimised fit perfectly with the description in the section above: high-rise reinforced concrete buildings with shear wall as lateral resisting system and flat slab as floor system, as the use of piles for the foundation system (Figure 3).

High-rise buildings have important lateral force requirements, due to lateral loads such as wind and earthquake. Our project location is also in a high seismic zone, most of its townships are located in soft alluvial plain which is mainly composed of sand, silt and clay and where strong ground motion and high amplification of local sediments can be expected. Moreover, the seism genic Sagaing fault is passing through about $50 \mathrm{~km}$ away from Yangon and it had experienced several earthquakes in the past.

The soil inform shows that Yangon peak ground acceleration (PGA) is $0.11 \mathrm{~g}$ to $0.2 \mathrm{~g}$ which will give a high requirement in the lateral force aspect of the foundation, and shear wall design. Therefore the main design problem, the ultimate strength and serviceability states will always be given by the earthquake load combinations. In our particular region, the potential earthquake magnitude is 7.5 and 7.0 in all the exploration bore-holes.

\section{Table 2. Maximum computed deflections allowed.}

\begin{tabular}{cc}
\hline Type of member & Deflection considered \\
\hline $\begin{array}{c}\text { Flat roofs not supporting or attached to } \\
\text { non-structural elements likely to be } \\
\text { damaged by large deflections }\end{array}$ & Immediate deflection due to live load L \\
$\begin{array}{c}\text { Floors not supporting or attached to } \\
\text { non-structural elements likely } \\
\text { to be damaged by large deflections }\end{array}$ & \\
$\begin{array}{c}\text { Roof or floors construction supporting } \\
\text { or attached to non-structural elements } \\
\text { likely to be damaged by large deflections }\end{array}$ & $\begin{array}{c}\text { The part of the total deflection occurring } \\
\text { after attachment of non-structural elements } \\
\text { (sum of the long-term deflection due to all } \\
\text { Roof or floors construction supporting } \\
\text { or attached to non-structural elements not } \\
\text { likely to be damaged by large deflections }\end{array}$ \\
\hline
\end{tabular}

Table 3. Maximum allowed drifts.

\begin{tabular}{|c|c|c|c|}
\hline \multirow{2}{*}{ Type of structure } & \multicolumn{3}{|c|}{ Risk category } \\
\hline & I or II & III & IV \\
\hline Shear wall & $0.020 \mathrm{~h}$ & $0.015 \mathrm{~h}$ & $0.010 \mathrm{~h}$ \\
\hline
\end{tabular}




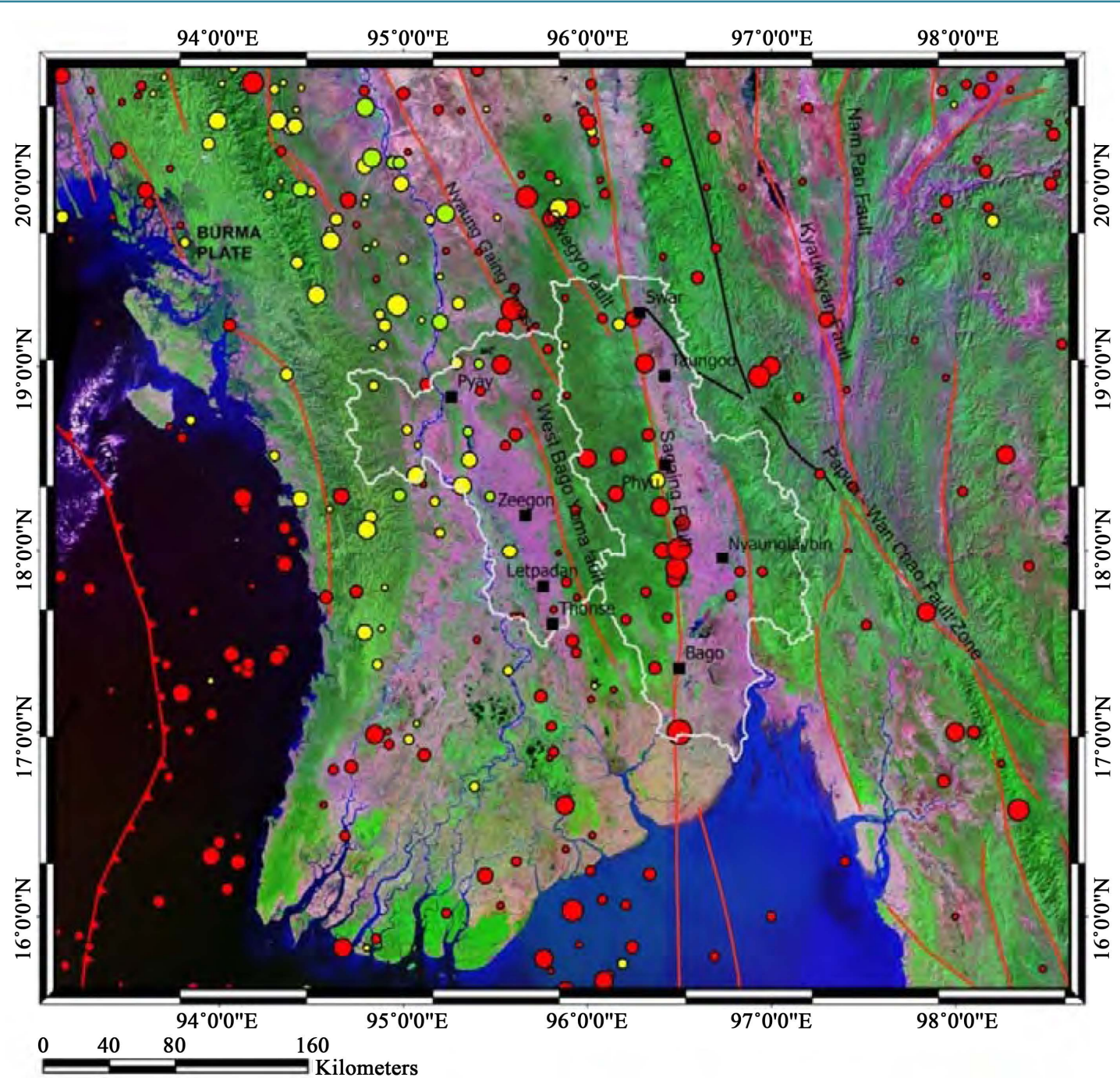

Figure 3. Seismic events 1900-2011 in Yangon (Red $\leq 40 \mathrm{~km}$, Yellow $>40$ and $<80$, Green $\geq 80 \mathrm{~km}$ ).

\subsection{Optimisation}

\subsubsection{Floor Optimisation}

So, in order to carry out the long-term deflection analysis, firstly we shall create the load combination that does successfully fit the ACI 318 definition. The load combination is a linear combination of three different loads (Table 4).

The load combination used in the analysis is:

$$
\begin{gathered}
\text { (INMEDIATE ALL LOADS) } \\
+ \\
\text { (LONGTERM SUSTAINED) } \\
- \\
\text { (INMEDIATE SUSTAINED) }
\end{gathered}
$$

After the calculation, the results are as shown in Figure 4.

After the long-term deflection is carried out, we just need to propose a new layout and compare the limit deflection with the new layout; this process is an iterative process. Table 5 summarises the results from the slab optimisation. 


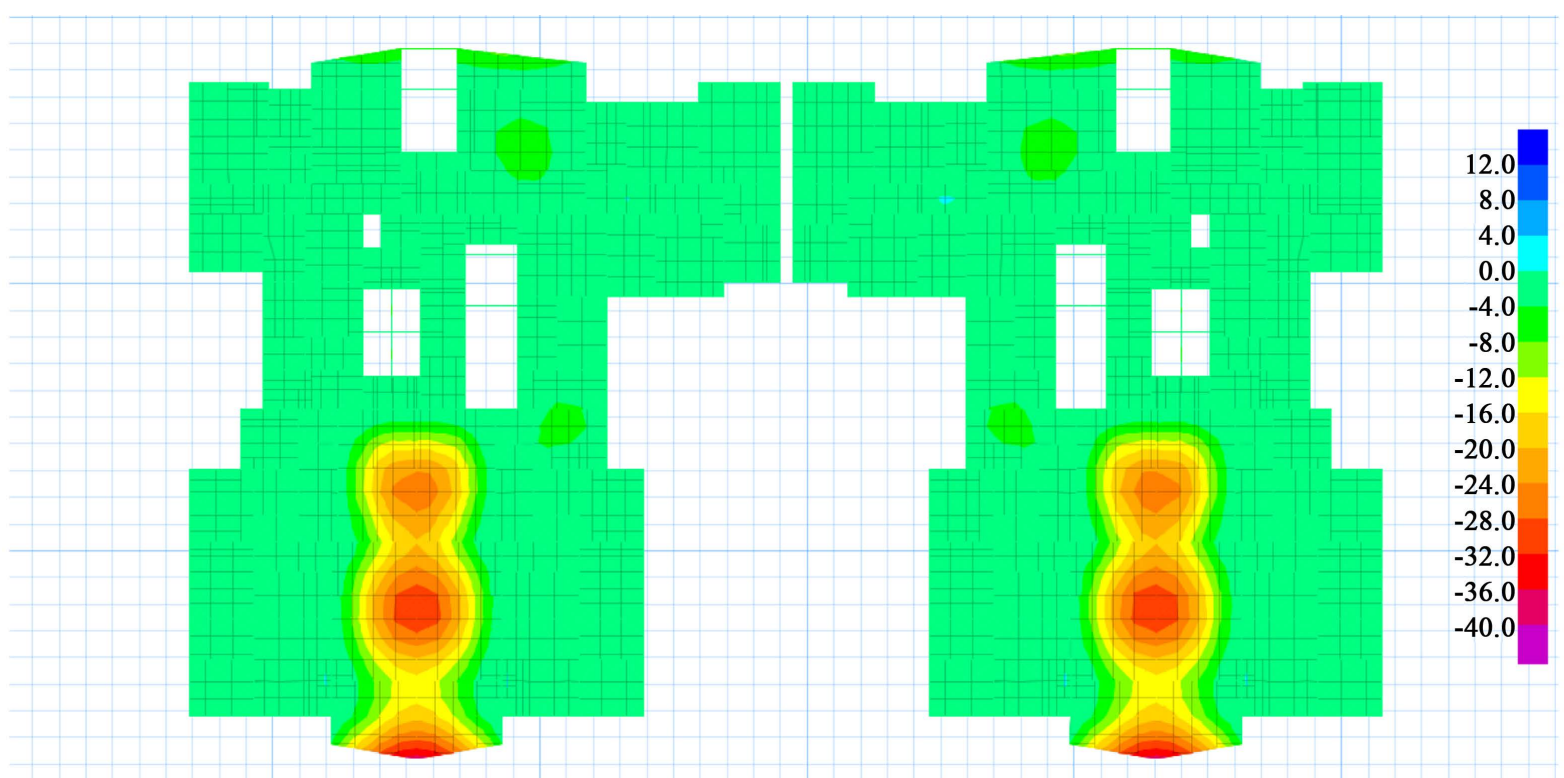

Figure 4. Slab long-term deflections.

Table 4. Long-term load combination.

\begin{tabular}{ccc}
\hline Load name & Analysis Type & Load Combination \\
\hline INMEDATE & Nonlinear (Cracked) & $1.00 \mathrm{DL}+1.00 \mathrm{LL}$ \\
ALL LOADS & & \\
LONGERM & Nonlinear (Long Term Cracked) & $1.00 \mathrm{DL}+0.25 \mathrm{LL}$ \\
SUSTAINED & Nonlinear (Cracked) & $1.00 \mathrm{DL}+0.25 \mathrm{LL}$ \\
INMEDIATE & & \\
SUSTAINED &
\end{tabular}

Table 5. Deflection after optimisation.

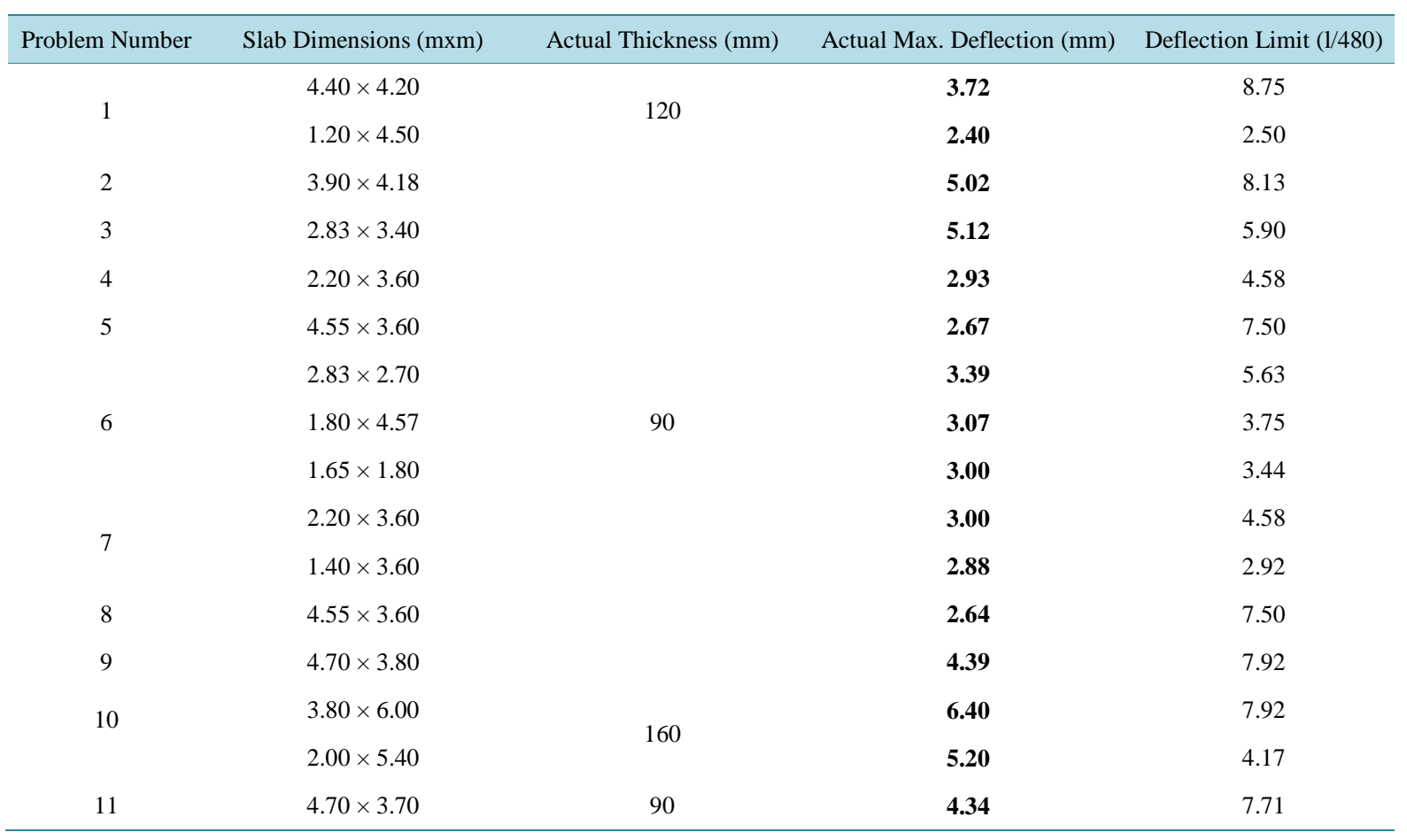


The slab will be optimised considering two different slabs, the ones similar to those on the 2nd floor and similar to the ones on the 15th floor; there is not a great difference between both of them, but an accurate analysis will provide a better result.

Taking into account that the amount of steel is invariant in the economisation of the slab, Table 6 resumes the concrete spared in the construction of buildings \#1 and \#2.

\subsubsection{Shear Wall Optimisation}

In our structure, the design main challenge are the lateral loads, due to the location, high seismic zone, and the own characteristic of a high-rise building (33 stories-high). Therefore we should understand perfectly the lateral displacement phenomenon. In our case after observing the story drift tables we can clearly determine that we have an issue with torsion. The lower balconies of both buildings have a great lateral displacement; this is caused by the torsion, which derives from a centre of mass distant from the centre of rigidity of the floor (Figure 5).

Therefore the solution the paper proposes is to reduce the shear wall quantity on the north part of the structure and increase it on the bottom part of it. This concept is carried out by means of opening on the shear-wall to diminish the shear-wall, and addition of a wall to reduce the drift (Figure 6).

As a summary we have open six $1.5 \mathrm{~m}$ openings in six different shear walls, with the counterpart of adding a $1.5 \mathrm{~m}$ shear wall on the south part of the building. The concrete and steel contents have clearly been reduced in the lateral structure usage. Moreover the lateral drift, weight of the structure and base shear, the three of them have all been improved. Thus, it is obvious that the structure has been optimised economically and in terms of structural behaviour (Table 7).

Table 8 shows the improvement in terms of materials consumed in the construction of the shear-wall in buildings \#1 and \#2.

Table 6. Summary of concrete spared.

\begin{tabular}{ccccc}
\hline Floor Type & $\begin{array}{c}\text { Optimised Concrete } \\
\text { per Floor }\left(\mathrm{m}^{3} \mathrm{C} 30\right)\end{array}$ & $\begin{array}{c}\text { Original Concrete } \\
\text { per Floor }\left(\mathrm{m}^{3} \mathrm{C} 30\right)\end{array}$ & $\begin{array}{c}\text { Number of Floors } \\
\text { Total Concrete Saved } \\
\left(\mathrm{m}^{3} \mathrm{C} 30\right)\end{array}$ \\
\hline 2nd Floor & 128.5 & 139.8 & 31 & $\mathbf{3 6 1 . 8}$ \\
15th Floor & 131.8 & 143.3 & 1 & \\
\hline
\end{tabular}

Table 7. Drifts after optimisation.

\begin{tabular}{ccccc}
\hline Story & Load Combination & Dir. & Prelim. Maximum Drift (m) & Actual Maximum Drift (m) \\
\hline & $0.9 D L+1.02 E X$ & & & \\
& $0.9 D L-1.02 E X$ & & & \\
& $0.9 D L+1.02 E X$ & $X$ & $1 / 292$ & \\
$19^{\text {th }}$ & $0.9 D L-1.02 E X$ & & & \\
& $0.9 D L+1.02 E X$ & & & \\
& $0.9 D L-1.02 E X$ & & & \\
\hline
\end{tabular}

Table 8. Lateral and vertical load resisting system optimisation summary.

\begin{tabular}{cccc}
\hline Construction Concrete Type & Optimised Concrete $\left(\mathrm{m}^{3}\right)$ & Total Concrete Saved (\%) & Optimised Steel (tHRB 500) \\
\hline C30 & $\mathbf{1 1 9 . 3 4}$ & 2.625 \\
C35 & $\mathbf{0 . 1 9}$ & 0.011 \\
C40 & $\mathbf{0 . 1 9}$ & 0.010 \\
C45 & $\mathbf{1 . 2 5}$ & 0.071 \\
C50 & $\mathbf{- 1 0 . 5 7}$ & -0.229 \\
\hline
\end{tabular}




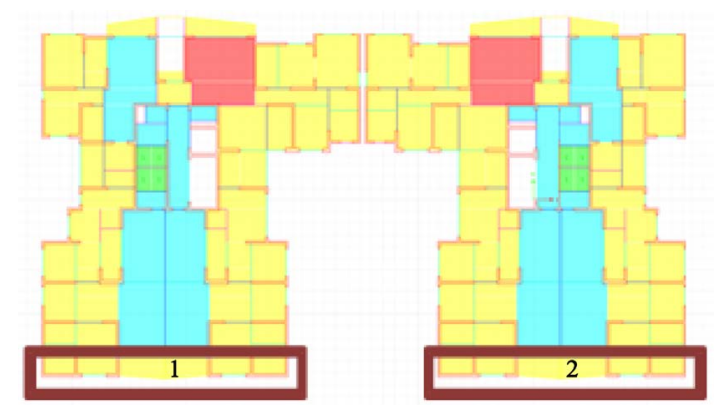

Figure 5. Maximum lateral displacement zone.
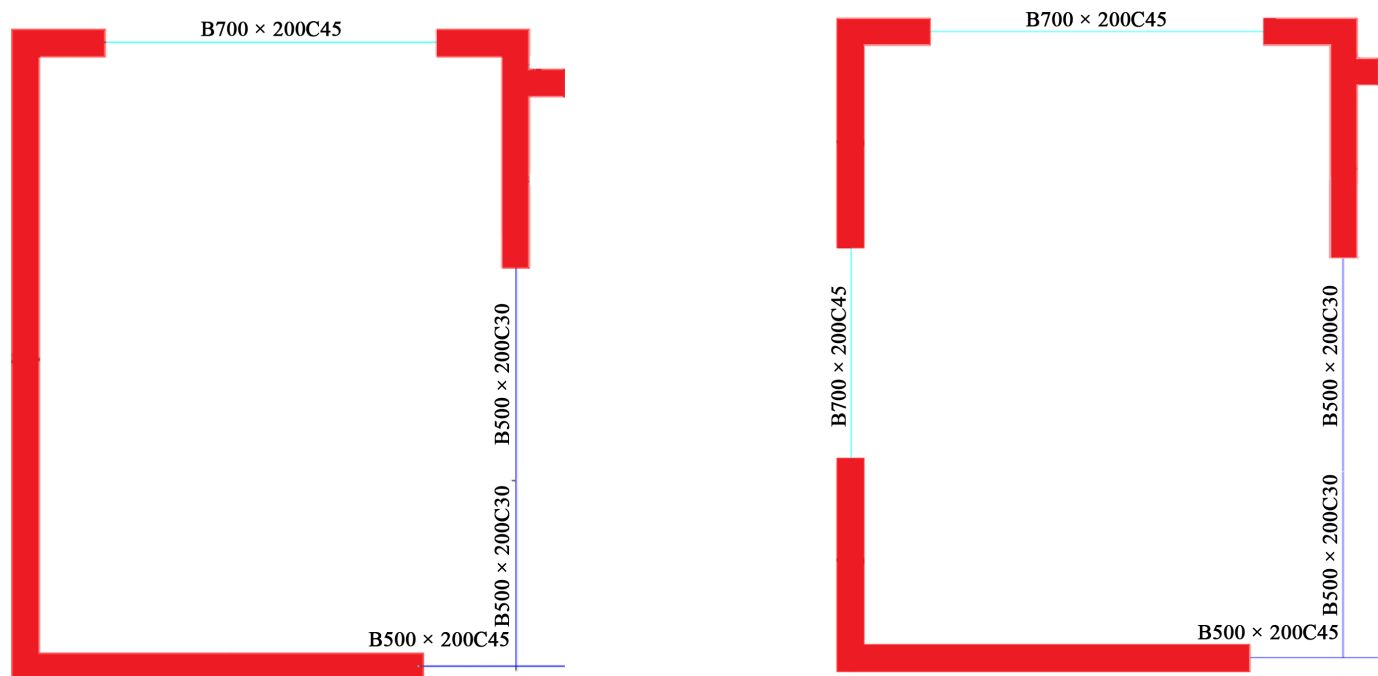

Figure 6. Shear-wall opening (red).

\subsubsection{Foundation Optimisation}

I have been described that the upper structure optimisation will provide lower requirements on the piles. The preliminary maximum axial strength of the pile is $3500 \mathrm{kN}$, which is not a sufficient margin in terms of improvement, therefore a possible solution is considered is the post grouting piles. Post grouting consist on the addition of mortar to the soil near the pile, it enhances the effective pile diameter, moreover, improves the bond between soil and pile by means of increasing the skin friction between them.

After a study by the consultant firm Myanmar Zhi Geotechnical Engineering Service, it is determined that the post grouted pile capacity ascend up to $6500 \mathrm{kN}$ axial resistance, based on ASD method defined in chapter 3. Thus, we can highly reduce the number of piles with an addition on the cost.

The new layout principal focus is to place the piles under the walls, so that the punching shear will be decreased and we can reduce the raft thicknesses. I consider that the increase of the piles will reduce the total number of piles around $60 \%$. After the optimisation process, the results are as shown in Table 9 and Table 10 .

\subsection{Structural Behaviour Comparison}

\subsubsection{Foundation System Comparison}

The improvement in terms of foundations is focused in the number of piles used and the solution of the punching shear issue, on the other hand we have the deflection increase counter effect. Figure 7 and Table 11 show the comparison between both, the initial and the optimised structure behaviour.

\subsubsection{Floor System Comparison}

The optimisation of the slab aims to achieve a deflection within the design criteria that is reduced with respect the original one. Figure 8 shows this increase. 

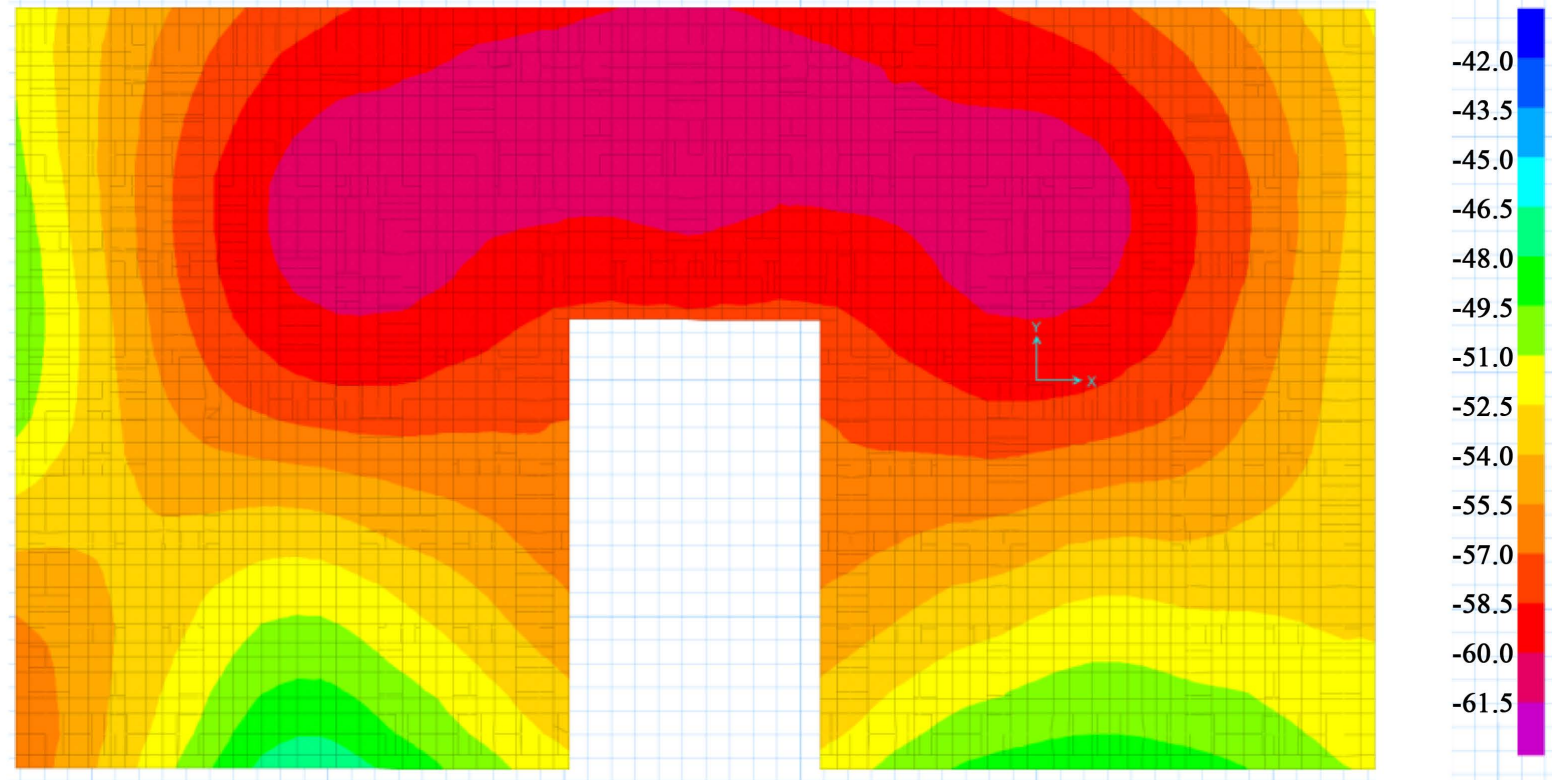

(a)
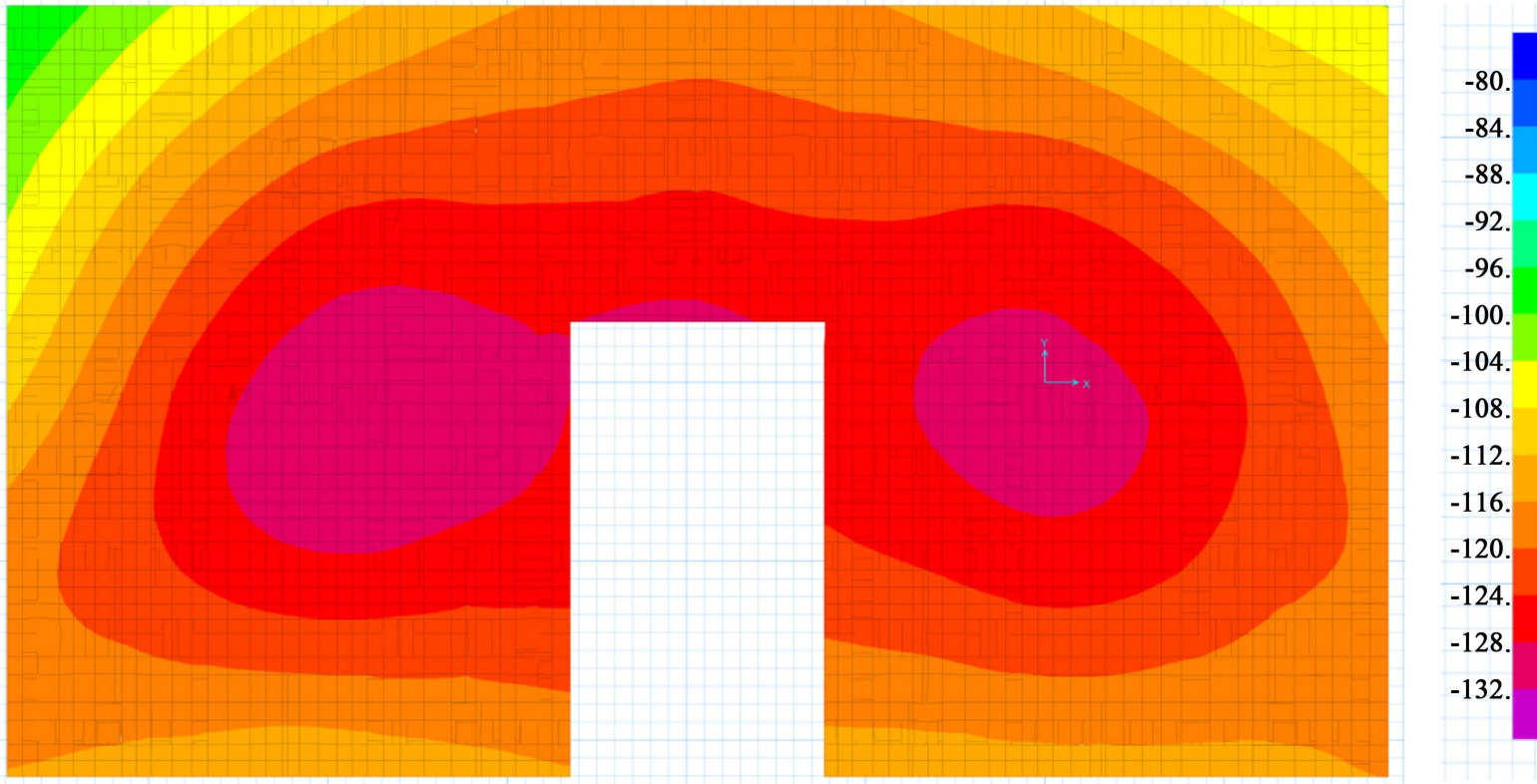

(b)

Figure 7. Deflection comparison. (a) Original; (b) Optimised.

Table 9. Foundation optimisation summary I.

\begin{tabular}{cccc}
\hline Element & Initial Layout & Optimised Layout 1 & Optimised Layout 2 \\
Piles (\#) & 305 & 162 & 162 \\
Raft thickness (mm) & 1700 & 1700 & 1.01900 \\
Punching shear (max) & 3.96 & 132 & 136 \\
Maximum deflection (mm) & 70.5 & 135 & 1.81 \\
\hline
\end{tabular}




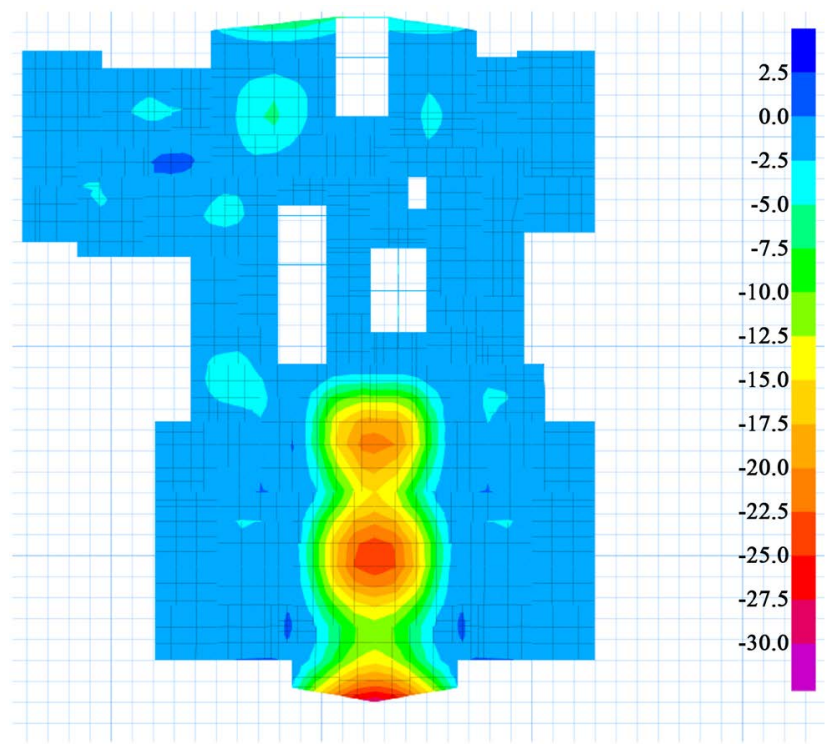

(a)

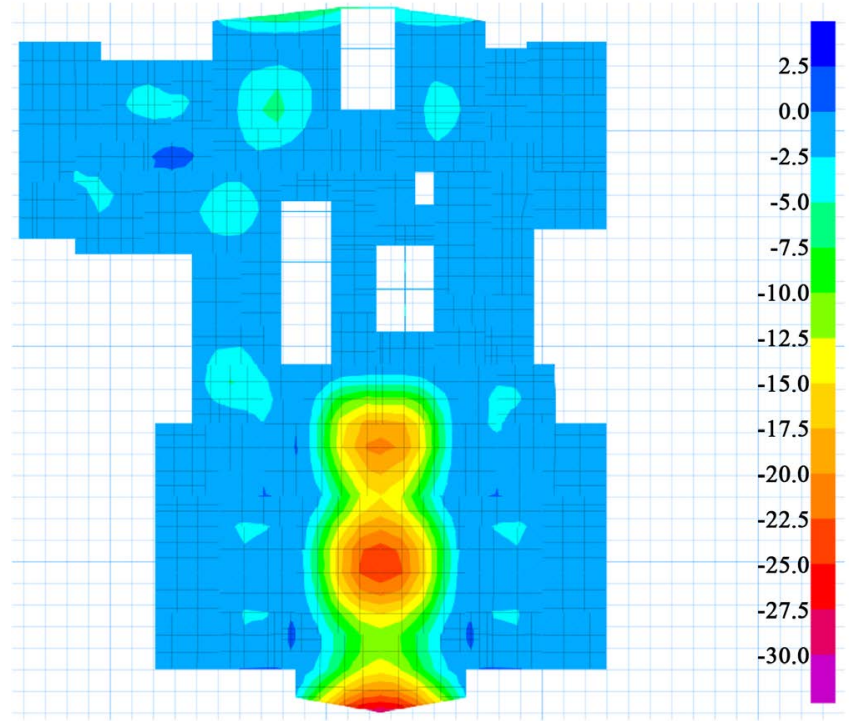

(b)

Figure 8. Deflection comparison. (a) Original; (b) Original.

Table 10. Foundation system optimisation summary II.

\begin{tabular}{ccc}
\hline Construction Type & Total Concrete Saved $\left(\mathrm{m}^{3} \mathrm{C} 50\right)$ & Total Steel Saved (t HRB 500) \\
\hline $\begin{array}{c}\text { Foundation } \\
\text { Raft }\end{array}$ & 2165 & 49 \\
\hline
\end{tabular}

Table 11. Punching shear comparison.

\begin{tabular}{lcc}
\hline & Original Layout & Optimized Layout \\
\hline & 3.9609 & 1.0047 \\
Maximum punching shear & 3.1796 & 1.0192 \\
& 2.3574 & 0.9760 \\
0.9494 \\
\hline
\end{tabular}




\subsubsection{Floor System Comparison}

The main criterion used is the drift along the height and the deflection of the high-rise building. The following figure displays the initial drift and the optimised drift, showing that there is an improvement even though the save in concrete and steel due to the reduction of shear-wall area (Figure 9).

\subsection{Results}

The optimisation of the Golden City is a project which has not been already successfully completed, it is still under construction, and this thesis is working in parallel with the design company and the construction company to have a better cost in the overall construction. Buildings \#1 and \#2 where optimised with respect the original design, afterwards the designing company used that process with buildings \#5, \#6 and \#7. As a result the optimisation improvements results of those three buildings is severely reduced compared with buildings \#1 and \#2 (Table 12 and Table 13).

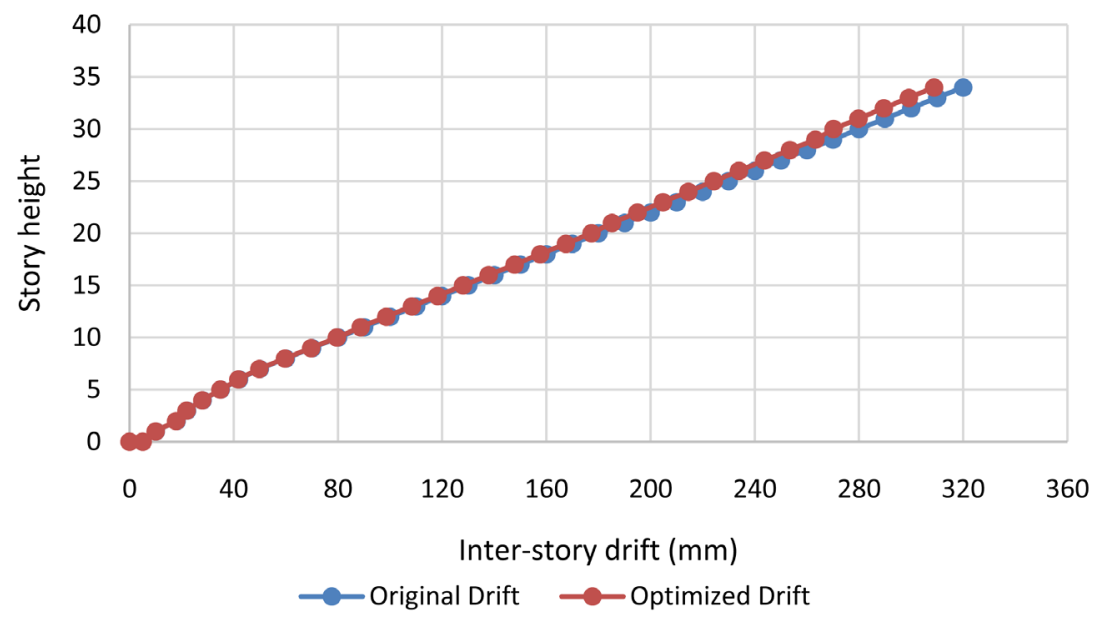

Figure 9. Critical drift comparison.

Table 12. Golden city foundation optimisation cost summary.

\begin{tabular}{cccc}
\hline & Pile Concrete & Raft Concrete & Raft Steel \\
\hline Unit Price & $700 ¥ / \mathrm{m}^{3}$ & $700 ¥ / \mathrm{m}^{3}$ & $3900 ¥ / \mathrm{m}^{3}$ \\
Optimised Cost & $1,271,200 ¥$ & $407,400 ¥$ & $191,000 ¥$ \\
\end{tabular}

Table 13. Golden city superstructure optimisation cost summary.

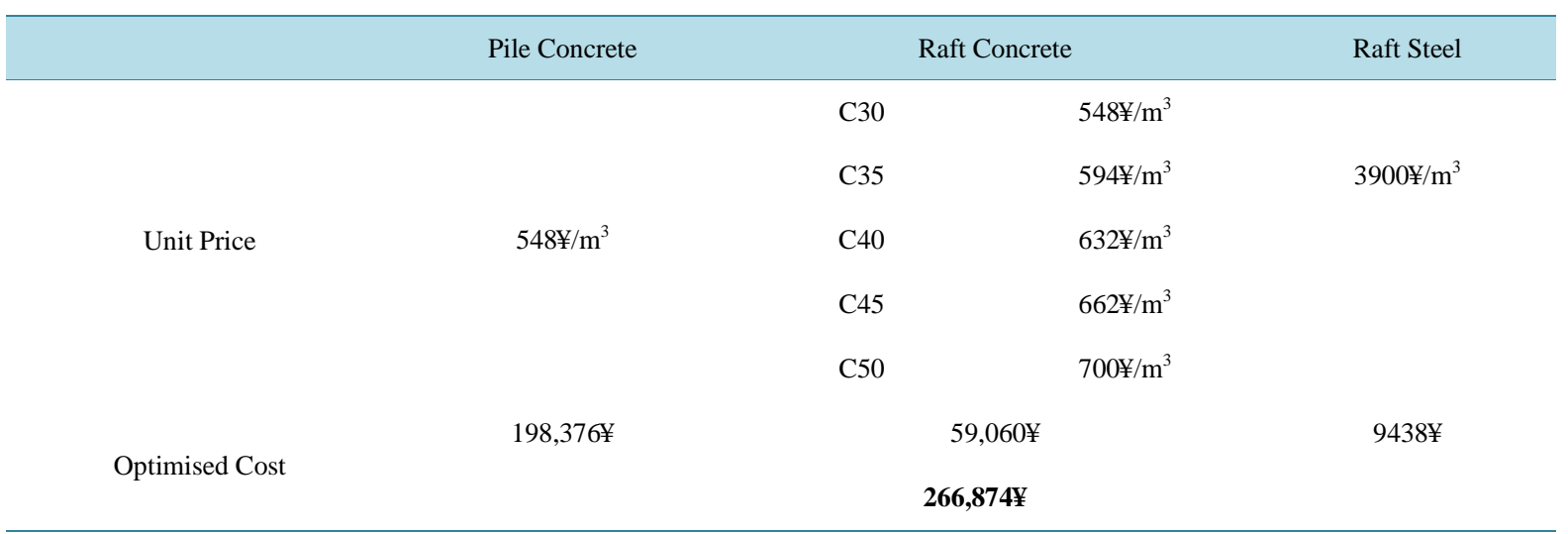




\section{Conclusion}

This paper has proven that it is possible to define a guideline to optimise high-rise residential reinforced concrete buildings, within the EEUU IBC and its referent codes building codes scope. Post grouting, shear-wall reduction and slab reduction have been shown to be an effective way of reducing the overall cost of the structure, but with the additional improvement of the structure's behaviour. For further studies I would like to expand this research to other building types or building codes.

\section{Acknowledgements}

The authors are grateful to the members of the Research Institute of Structural Engineering and Disaster Reduction of Tongji University, as well as the Civil Engineering School of Tongji University, for all the insight and support to our endeavour in carrying out this study. I would like also to thank to my tutor XiongHaibei for this two years of support.

\section{References}

[1] Jayachandran, P. (2009) Design of Tall Buildings: Preliminary Design and Optimization. 13th National Workshop on High-Rise and Tall Buildings, University of Hyderabad, Hyderabad, May 2009, Keynote Lecture.

[2] Katkhoda, A. and Knaa, R. (2012) Optimization in the Selection of Structural Systems for the Design of Reinforced Concrete High-Rise Buildings in Resisting Seismic Forces. Energy Procedia, 19, 269-275. http://dx.doi.org/10.1016/j.egypro.2012.05.206

[3] Abdo, M.A.-B. (2012) Modeling of Shear-Wall Dominant Symmetrical Flat-Plate Reinforced Concrete Buildings. International Journal of Advanced Structural Engineering, 4, 2. http://dx.doi.org/10.1186/2008-6695-4-2

[4] Yousef, Z., Naziri, R. and Hamedani, R. (2012) Effect of Layout and Size Optimization Conditions in Architectural Design of Reinforced Concrete Flat Slab Buildings. Bulletin of Environment, Pharmacology and Life Sciences, 2, 6268.

[5] Greeshma, S. and Jaya, K.P. (2008) Seismic Behaviour of Shear Wall-Slab Connection. 14th World Conference on Earthquake Engineering, Beijing, 12-17 October 2008, Article ID: 14-0059.

[6] Leonga, T.K. and Huat, C.S. (2013) Sustainable Design for Unpiled-Raft Foundation Structure. Procedia Engineering, 54, 353-364. http://dx.doi.org/10.1016/j.proeng.2013.03.032

[7] IBC-2009 (International Building Code).

[8] ACI 318M (American Building Institute).

[9] ASCE/SEI 7-10 (American Society of Civil Engineers). 